\title{
APORTACIÓN METODOLÓGICA PARA EL ESTUDIO DE COLECCIONES BIBLIOGRÁFICAS ANTIGUAS EN EL ECUADOR: LOS LIBROS PATRIMONIALES DEL FONDO “UNIVERSIDAD CENTRAL DEL ECUADOR 1485-1960"
}

Francisco González de la Fuente

Universidad Central del Ecuador

Recibido: 05 - noviembre - 2015, aprobado 25 - noviembre - 2015

\section{Resumen}

Este artículo desgrana la metodología empleada para el estudio de los libros antiguos custodiados por el Ârea Histórica de la Universidad Central del Ecuador, investigación centrada en la recuperación de la memoria histórica de la Biblioteca Universitaria y de las colecciones antiguas con presencia en su repositorio, incluido dentro del Fondo bibliográfico "Universidad Central del Ecuador 1485-1960", aportando un resumen de sus conclusiones.

Palabras clave: Universidad Central del Ecuador, biblioteca universitaria, colecciones antiguas, libro antiguo

\begin{abstract}
This paper explains the methodology applied to the study of the ancient books kept by the Historical Area of the Central University of Ecuador, research focused on the recovery of the historical memory of its University's Library and the ancient collections present in the Bibliographical Reserve "Universidad Central del Ecuador 1485-1960", and also includes a summary of its conclusions.

Keywords: Central University of Ecuador, university's library, ancient collections, ancient books.
\end{abstract}




\section{Introducción}

El Área Histórica del Centro de Información Integral de la Universidad Central del Ecuador custodia un amplísimo fondo bibliográfico, de decenas de miles de ejemplares, denominado "Universidad Central del Ecuador 1485-1960". En él se reúnen todos los libros tanto de la Biblioteca Universitaria, luego Biblioteca General, como los de algunas librerías menores de diferentes facultades, que por su antigüedad han sido retirados de las estanterías de uso frecuente. Entre todos ellos encontramos 3.215 libros considerados antiguos ${ }^{1}$.

Por iniciativa de la coordinadora del Área Histórica, Natasha Sanmartín, con el apoyo de la directora del Centro de Información Integral, María del Carmen Gaibor, se promueve una investigación centrada en el análisis tanto de la propia historia de la Biblioteca de la Universidad Central como de su fondo antiguo, es decir, de esos 3.215 volúmenes. Esto último implicaba elaborar un listado con las obras presentes y la asignación de materias para su futuro reordenamiento, así como desentrañar de qué manera fueron adquiridas por la Universidad. Además, se solicitó recuperar la memoria de antiguas colecciones que pudieran estar presentes entre ellos, puesto que gran parte de estas obras ya circulaban en tiempos de la Real Audiencia de Quito, por tanto, con anterioridad al nacimiento de la propia Universidad Central.

En el desarrollo de esta investigación se reunió inicialmente una amplia bibliografía sobre la Historia del Libro, de la Cultura (centrados en el mundo universitario) y de las bibliotecas históricas quiteñas, mientras se realizaba una evaluación inicial del fondo para diseñar una metodología capaz de alcanzar los resultados esperados. Con esa información asimilada, se procedió, de un lado, a la búsqueda de documentación escrita relevante de época en diferentes archivos quiteños ${ }^{2}$, en la que el concurso de la Lcda. Martha Flores en los dos primeros meses resultó esencial ${ }^{3}$. De otro, se procedió al reconocimiento individualizado de cada uno de los volúmenes, generando una base de datos capaz de sistematizar la información histórica que acompaña a cada ejemplar, como vía de rastreo de posibles filiaciones que permitieran, a la postre, recuperar la existencia de fases o momentos en los cuales diferentes libros pudieron haber compartido anaqueles.

La investigación tomó un tiempo de cinco meses, entre enero y mayo de 2015, resultado de la cual fue el informe presentado bajo el título "Investigación de las Colecciones Antiguas de las Reservas del Área Histórica", que el presente artículo

1 Según el criterio empleado para nuestra investigación, se considera libro antiguo a todo aquél publicado con anterioridad a 1801, más aquellos que, pese a ser editados con posterioridad a esa fecha, pertenecen a un título u obra que tenga ejemplares que sí entran en el periodo acotado.

2 Con resultados positivos tenemos el Archivo General de la Universidad Central (AGUCE), Archivo Nacional del Ecuador (ANE), Archivo de la Curia Metropolitana (ACM). Quedaron fuera de nuestro alcance el Archivo de la Orden Jesuita y otros de titularidad privada que pueden arrojar más datos sobre las cuestiones aquí analizadas.

3 Sin las observaciones, indagaciones e ideas expresadas por la mencionada historiadora el estudio habría resultado incompleto. Igualmente, se han de agradecer los consejos recibidos por diversos historiadores del libro antiguo consultados al hilo de la investigación: Carlos Ciriza, María Pilar Ponce-Leiva, María Antonieta Vásquez Hahn, María Idalia García Aguilar, Juan David Morillo Sandoval, Pedro Rueda Ramírez, Francisco Piñas y Rocío Pazmiño. 
resume en gran medida ${ }^{4}$. No obstante, queremos aprovechar este espacio para hacer especial hincapié en la oportunidad de una metodología de análisis pormenorizado de la información histórica que aportan los libros en sí, como una fuente poco empleada en el Ecuador y de gran potencialidad, por cuanto al reconocer estos rasgos se puede trasladar a otras bibliotecas históricas por medio de tipologías para la recomposición de colecciones antiguas que estén presentes tanto en el fondo "Universidad Central del Ecuador" como en otros lugares.

Esperamos con ello apoyar la sensibilización frente a esta fuente de información, de tal manera que se camine hacia la generación y aplicación de normas de conservación específicas que permitan su protección y estudio, puesto que en ocasiones puede considerase a los elementos que la componen superfluos, y por tanto, eliminables.

\section{La materialidad frente al documento escrito}

Cuando la arqueología se ocupa de periodos para los que se cuenta también con documentación escrita resulta habitual que nazca el debate entre cuál de las dos fuentes tiene primacía a la hora de generar un discurso que refleje más fidedignamente la realidad estudiada, o cómo establecer un puente entre ambas disciplinas $^{5}$. Por la propia evolución de las metodologías de investigación histórica, en las que el estudio del documento histórico fue anterior al desarrollo de la técnica arqueológica de carácter científico, se tendía a considerar que la segunda era una ciencia auxiliar de la primera, y por tanto, era tan sólo el reflejo de lo expresado por la documentación escrita y no tenía explicación fuera de ella. La materialidad dejada por los grupos humanos del pasado, no obstante, es tozuda, y ha quedado claro que muchas veces la arqueología muestra evidencias que la documentación escrita no recoge o que retrata de una forma muy diferente a como la percibimos en campo, ya sea por los intereses o por las propias concepciones de quienes la produjeron. Cada caso obliga por tanto a un estudio detenido de ambas fuentes de información para alcanzar soluciones satisfactorias.

Aunque para los periodos cronológicos en que se ubican los libros impresos existe no sólo una documentación escrita numerosa y elocuente sino también una abundante serie de trabajos de investigación que se han ocupado de tratar diferentes aspectos sobre los mismos, sigue siendo pertinente recuperar la información que el hecho material en sí, es decir, los propios libros, llevan consigo. En muchas ocasiones nos permitirán adentrarnos en cuestiones que no parecían abiertas por falta de datos, y en otras, poner de manifiesto distorsiones derivadas del empleo exclusivo del escrito como fuente de información. Y dado que estamos tratando de alteraciones sobre el libro impreso original que tienden a responder a lógicas

4 Se espera la publicación de ese informe como libro a lo largo de 2016, incluyendo los listados de obras y antiguos propietarios elaborados al efecto, así como un denso apartado en figuras y gráficos que apoyan diferentes aspectos del discurso. Por causa de espacio, no podemos reproducir esa información aquí, por lo que remitimos a su consulta al lector interesado.

5 Moreland, John (2001): Archaeology and text, Sheffield, Duckworth; Moreland, John (2013): "Arqueología histórica. Más allá de las "evidencias"”, en Quirós Castillo, Juan Antonio (ed.), La materialidad de la Historia. La arqueología en los inicios del siglo XXI. Madrid, Akal, pp. 37-65. Referencia bibliográfica obtenida gracias a Carlos Tejerizo García. 
que afectan a más de un ejemplar, y que por tanto en su reconocimiento podemos establecer filiaciones entre libros, es posible y deseable la elaboración de tipologías como las diseñadas por la arqueología. Con un número creciente de rasgos reconocidos y publicados, sumado a la información aportada por la documentación escrita, se puede trabajar en su ubicación cronológica, resultando de ello la generación de referencias para que futuros investigadores puedan encajar de una manera sencilla los libros que estén estudiando en un esquema general a todos.

Cuando nos referimos a la información histórica que de manera individual muestra cada libro, estamos hablando de los elementos que son posteriores a la impresión original del volumen, y que lo van marcando en su tránsito existencial por acumulación o pérdida. Entre ellos contamos el tipo de cubierta, inscripciones y alteraciones sobre la misma, signaturas antiguas que se hayan conservado en su exterior o en su interior, marcas de propiedad (manuscritas, en sello o ex libris, generalmente presentes en las primeras páginas del libro), anotaciones, restauraciones, patologías, etc. Todos son datos sistematizables y que permiten rastrear la existencia de procesos comunes a varios ejemplares, muy entremezclados estratigráficamente pero finalmente reconstruíbles.

Evidentemente, dado el incontable número de propietarios individuales que han existido y dejado constancia palpable de ello a lo largo de los siglos, considerando cada uno de ellos como una fase del libro, la ramificación estratigráfica se antoja inabarcable. No obstante, en palabras de Martín Abad:

Los ejemplares de un fondo están unidos naturalmente por su pertenencia a una persona o a una institución histórica antes de quedar incorporados al conjunto de ejemplares, unidos accidentalmente, que constituyen una biblioteca histórica actual. El bibliotecario debe atender a la singularización de esas piezas, pero a veces se ha perdido el sentido histórico al organizar ese conjunto accidental que es la colección, incluso al preparar las unidades de conservación para su catalogación y para su posterior consulta" ${ }^{6}$.

Si en los procesos de catalogación se incluyen espacios donde reflejar la presencia o ausencia de los elementos arriba mencionados como parte habitual de su trabajo, el investigador irá fácilmente encontrando los rasgos que le sean de interés.

A esta aportación se une la de Navarro Bonilla, específicamente centrada en marcas de propiedad y de lectura, explicando la utilidad de su registro:

[...] lejos de constituir un material intrascendente, todos aquellos añadidos (literales o gráficos) sobre el ejemplar impreso ofrecen valiosos datos no solo sobre los modos de escritura sino también sobre las modalidades en que el impreso entró a formar parte de una colección, se leyó, anotó, marcó la impronta original por cada uno de los lectores y propietarios del ejemplar a lo largo de los años" ".

6 Martín Abad, Julián (2003): "Del ejemplar, o de ciertas historias (casi) siempre pasadas por alto" en Docampo Capilla, Javier (ed.): I Jornadas sobre Patrimonio Bibliográfico en Castilla La Mancha: actas: 12, 13 y 14 de noviembre, Alcázar de Toledo. Del ejemplar, o de ciertas historias (casi) siempre pasadas por alto. Toledo, Junta de Comunidades de Castilla-La Mancha, p. 16.

7 Navarro Bonilla, Diego (2003): "Las huellas de la lectura: marcas y anotaciones manuscritas en impresos de los siglos XVI a XVIII" en Castillo Gómez, Antonio (ed.): Libro y lectura en la Península Ibérica y América (siglos XIII a XVIII). Las huellas de la lectura: marcas y anotaciones manuscritas en impresos de los siglos XVI a XVIII. Valladolid, Junta de Castilla y León, p. 246. 
En la revisión de los volúmenes antiguos del fondo "Universidad Central del Ecuador 1485-1960" hemos visto rasgos que se repiten numerosas veces, y que de hecho se encuentran también presentes en libros de otras bibliotecas históricas quiteñas visitadas a lo largo de la investigación. Dado que este estudio se está adentrando en una problemática casi virgen en el Ecuador, serán éstos los que se pondrán de relieve. Junto a ellos, hay otros cuya presencia puede darse en tan sólo un ejemplar, de los que sólo destacaremos algunos por su interés singular.

Reconociendo individualmente cada libro, trabajamos sobre los volúmenes que hoy día se conservan en un fondo. Puede parecer baladí pero es precisamente el factor que va encaminado a reducir en el mayor grado posible el desacuerdo que muchas veces muestran algunas fuentes documentales con la realidad que reflejan. Nos referimos, por ejemplo, a que en un acta de traspaso de inventario se pueda mentir, por la razón que sea, indicando que se tienen libros que en realidad se han perdido, o que se oculten otros porque están prohibidos, como pasaba con ejemplares perseguidos por la Inquisición. En otros casos estos inventarios no son prolijos en detalles y no permiten conocer a ciencia cierta si el volumen al que se están refiriendo es exactamente el mismo tenemos entre manos. Al trabajar sobre el libro, evitamos que la fuente nos engañe, y podemos encontrar sorpresas que no pensábamos topar, como el destino de determinada colección, fraccionada por avatares históricos que pueden haber pasado inadvertidos al no tener constancia de ellos en la documentación escrita.

Además, se evitan conclusiones apriorísticas, como identificar determinado ejemplar como parte del Fondo Jesuita sólo por su antigüedad, tendencia extendida entre los curadores de bibliotecas históricas quiteñas. Creando tipologías, insistimos, generamos guías para que cualquiera pueda reconocer por el aspecto exterior del libro determinadas fases en su tránsito vital, y, publicando esas informaciones, poco a poco se podrán reconstruir viejas colecciones cuya memoria ha quedado enterrada, lo que supone un enorme apoyo empírico para los investigadores de la historia de la cultura y de las bibliotecas.

\section{El libro antiguo en el Ecuador. Breve estado de cuestión}

No obstante, existen para Ecuador numerosos estudios en los que el libro antiguo forma parte de los elementos manejados por los historiadores. La producción historiográfica suele girar, como es lógico, en torno a la historia de la cultura, tanto en época colonial como republicana, con una especial presencia del mundo universitario, por ser epicentro de renovación de ideas o, por el contrario, de contención de las mismas ${ }^{8}$.

8 Sin afán de exhaustividad: Espinoza, Jaime (1931 Enero-Marzo): "La Universidad Central en los primeros cien años de vida republicana (I)", en Anales de la Universidad Central, No. 275, Apéndice; y sucesivas; Moncayo De Monge, Germania (1944): La Universidad de Quito en tres siglos. 1551-1930. Quito, Imprenta de la Universidad Central; Lozano Cabrera, M. (1950 octubre): "Origen y desarrollo de la universidad ecuatoriana", en Revista de Filosofia, Letras y Ciencias de la Educación, No. 8 (año III), s. p.; Sánchez Astudillo, Miguel (1959): Textos de catedráticos jesuítas en el Quito colonial: Estudio y bibliografia. Quito, Casa de la Cultura Ecuatoriana; Vargas, José María (1965): Historia de la cultura ecuatoriana. Quito, Casa de la Cultura Ecuatoriana; Romo S., Luis A. (1980): "La investigación científica en 150 años de vida republicana" en Mora Ortega, Luis (coord): Arte y Cultura. Ecuador: 1830-1980. La investigación científica en 150 años de vida republicana. Quito, Corporación Editora Nacional; Mena Mena, Camilo (1980): "La Universidad: cultura en 150 años de Vida Republicana" en Mora Ortega, Luis (coord): Arte y Cultura. Ecuador: 1830-1980. La Universidad: cultura en 150 años de Vida Republicana. Quito, Corporación Editora Nacional; Roig, Arturo Andrés (1984): Humanismo 
De otro lado, aunque en mucho menor número, contamos con investigaciones en las que el libro antiguo ha sido el centro de interés. De un lado, podemos contar los catálogos publicados como forma de dar a conocer el contenido de algunas bibliotecas históricas ${ }^{9}$, y de otro, de mayor profundidad, preocupado por las formas de circulación del mismo, generalmente en periodo colonial ${ }^{10}$.

Lo que todos ellos tienen en común es que tienden a basarse únicamente en la documentación escrita, salvo el caso de Keeding, que la conjuga con las marcas de propiedad que encontró en algunos libros del repositorio de la Universidad Central, por tanto, los mismos que han sido objeto de nuestro estudio, si bien no aportó los datos que recogió para su investigación, que podrían haber sido un excelente punto de partida para generar esa base empírica que señalábamos ${ }^{11}$. En los estudios sobre Historia de la Cultura es habitual recurrir a planes de estudios de las universidades coloniales, a las lecciones de los profesores universitarios que se han conservado y en general la producción cultural de la época analizada, así como a los inventarios de bibliotecas que han llegado a nuestros días, testamentos, actas de traspaso, expedientes del Registro de Ida de Navíos del Archivo de Indias, y otros testimonios contemporáneos que resultaran elocuentes, como cartas privadas o relatos de viajes. Parte de esta documentación también es utilizada cuando se ha intentado reconstruir la conformación y disgregación de repositorios antiguos, como es el caso del famoso Fondo Jesuita ${ }^{12}$.

\section{Metodología desarrollada para el estudio de los libros antiguos del fondo "Universidad Central del Ecuador 1485-1960"}

Explicada ya la motivación del desarrollo de una metodología en la que de manera sistemática se recogen todos los rasgos que componen la información histórica que encontramos en cada ejemplar, queda señalar qué elementos referenciales se poseían a la hora de enfrentar el caso concreto de los 3. 215 volúme-

en la segunda mitad del s. XVIII. Quito, Biblioteca Básica del Pensamiento Ecuatoriano ${ }^{\circ} 18-19$; Paladines Escudero, Carlos (1988): Pensamiento pedagógico ecuatoriano. Quito, BCE - Corporación Editora Nacional; Guerra Bravo, Samuel (1989): "La Cultura en época colonial”, en Ayala Mora, Enrique (ed.): Nueva Historia del Ecuador. Quito, Abya-Yala; Ponce Leiva, María Pilar (1998): "La educación disputada: Repaso bibliográfico sobre la enseñanza universitaria en la Audiencia de Quito", en Estudios de historia social y económica de América, No. 11, pp. 137-149; Lucena Salmoral, Manuel (1999): "El reformismo despotista en la Universidad de Quito", en Cuadernos del Instituto Antonio de Nebrija, No. 2, pp. 59-82; Keeding, Ekkehart (2005): Surge la nación: la Ilustración en la Audiencia de Quito. 1725 1872. Quito, Banco Central del Ecuador.

9 Para el caso concreto de la Universidad Central: Espín Lastra, Alfonso (1963): Libros coloniales de la Universidad de Quito. Catálogo General. Quito, Editorial Universitaria. Otro ejemplo: S.A.: Incunables y libros raros y curiosos de los siglos XV, XVI, XVII y XVIII, de la Sección llamada "Hispanoamericana”. Quito, Biblioteca Nacional, 1959.

10 El trabajo de Pedro Rueda resulta esencial en este campo. Ej.: Rueda Ramírez, Pedro José (2000): “La circulación de libros desde Europa a Quito en los siglos XVI-XVII", en Procesos: Revista Ecuatoriana de Historia, No. 15, pp. 3-20.

11 Keeding, Ekkehart (2005): Surge la nación..., op. cit., p. 36.

12 Barnadas, Joseph (1974): La Biblioteca jesuita de Quito en el siglo XVII. Iberoamericana Pragensia, No 8, pp. 151-181; Fierro-Renoy, Juan Francisco (2008): “Las bibliotecas de la Compañía de Jesús en la Real Audiencia de Quito" en Naranjo, Plutarco y Fierro-Benítez, Rodrigo (eds.), Eugenio Espejo: Su época y su pensamiento. Las bibliotecas de la Compañia de Jesús en la Real Audiencia de Quito. Quito, Corporación Editora Nacional. 
nes antiguos custodiados en el Área Histórica de la Universidad Central y cómo ello determinó el procedimiento para generar datos de análisis.

Primeramente, se buscó la documentación histórica que pudiera conservarse fruto de la gestión, durante más de siglo y medio de historia, de la Biblioteca Universitaria o General. Lamentablemente, no fue posible ubicar su paradero dentro del Archivo General de la UCE, y tampoco hubo suerte en el resto de archivos quiteños consultados, donde ocasionalmente sí aparece alguna información sobre este repositorio en relación a su vecindad con la Biblioteca Pública de Quito (desde su origen compartieron instalaciones en el viejo Caserón Universitario, actual Centro Metropolitano de Cultura, que había sido anteriormente sede del Colegio Máximo y de la Universidad San Gregorio Magno -jesuitas- y transformado pocos años después de la expulsión de la orden -1767- en la Universidad Pública Santo Tomás de Aquino ${ }^{13}$ ).

La bibliografía antigua tampoco era numerosa ni prolija, la mayoría publicaciones de los propios bibliotecarios en la revista Anales de la Universidad Central, como ampliaremos en el apartado de resultados. De hecho, parece que estos autores tampoco pudieron encontrar la documentación antigua de gestión de la Biblioteca Universitaria $^{14}$.

Por tanto, no contábamos con mucha referencia escrita sobre cómo la Biblioteca se hizo con su fondo antiguo o con el resto de libros adquiridos a lo largo del siglo XIX. Para el siglo XX ocasionalmente se dan en Anales noticias de adquisiciones de libros, más o menos detalladas según el momento.

Por último, en ocasiones el ordenamiento de una colección antigua que no ha sido alterado en mucho tiempo permite seguir de alguna manera si se respetaron procedencias. Lamentablemente, la Biblioteca General pasó por varios traslados y reordenamientos desde el propio siglo XIX, y al convertirse en el fondo "Universidad Central del Ecuador 1485-1960" a inicios del siglo XXI, se inventarió siguiendo un criterio cronológico. Por tanto, no quedaba rastro posible en el ordenamiento actual de un sentido histórico.

Así que la motivación del empleo de una metodología centrada en lo que cuentan los propios libros parte tanto de la motivación teórica arriba expuesta como de la ausencia de evidencias que permitieran llegar a conclusiones sólidas. Con lo que sí se contaba de inicio era con la excelente base de datos levantada por Breccia y Fugaro en 2005- 2006, a intermediación de la Unión Latina. Supuso una punto de partida esencial, por cuanto estos investigadores no sólo recogieron los datos básicos de catalogación (autor, título de la obra, lugar y año de impresión o impresor), sino que se detuvieron en establecer filiaciones entre ejemplares para reconstruir títulos, aunque en alguna ocasión eso llevó a la creación de títulos ficticios formados con ejemplares con muy diferente tránsito vital antes de su llegada

13 Vásquez Hahn, María Antonieta (2005): Luz a través de los muros. Biografía de un edificio quiteño. Quito, FONSAL, p. 147 y ss.

14 Barrera, Jaime (1937 Octubre-Diciembre): "La Biblioteca de la Universidad", en Anales de la Universidad Central, No. 302, p. 599. 
a la Biblioteca Universitaria ${ }^{15}$. Dado que estos investigadores generaron catálogo para otros repositorios ecuatorianos, animamos a su consulta y aprovechamiento en estudios futuros que se animen a seguir el camino que intentamos potenciar en estas páginas.

Los libros demostraron que al emplearse como fuente de información histórica podían suplir nuestras carencias iniciales en gran medida. Al examinarlos no sólo vimos esas alteraciones que permitían asociarlos entre ellos, sino numerosos sellos de gestión que la propia Biblioteca General fue empleando a lo largo de su existencia, lo que permitía comprender desde otro ángulo su evolución y su permeabilidad a los procesos de cambio de conocimientos de la propia Universidad Central, y, por ende, de la vida universitaria quiteña y ecuatoriana.

Registrar sistemáticamente esta información obligó evidentemente al análisis libro a libro de los 3. 215 ejemplares $^{16}$, para posterior tratamiento de la información una vez levantada la base de datos. Ello conllevó también la toma de aproximadamente 23.000 fotografías, una media de 7 por ejemplar, entre tomas generales y de detalle si el volumen lo requería.

Para hacer manejable la información era necesario crear una división de los rasgos con los que se iba a trabajar. Es una racionalización básica, susceptible de ser mejorada y profundizada por los expertos en técnicas de restauración y conservación, dado su conocimiento más profundo sobre encuadernación, composición química de tintas, análisis tipográficos, de patologías, etc. Con su contribución, dada su experiencia sobre los diferentes aspectos de la composición material de los libros antiguos, se pueden construir tipologías muy definidas en el futuro.

Creamos una base de datos empleando el programa Access, de manejo sencillo, empleando los siguientes grupos de variables:

- Edición (Autor, título, año, lugar de impresión y materia) ${ }^{17}$;

- Tipos de encuadernación;

- Tipos de alteración de cubiertas (en los lomos, generalmente);

- Análisis de los sistemas de inventario o catalogación antiguos que aún sean reconocibles en los lomos;

- Marcas de propiedad y escrituras en el interior de los libros;

Revisemos en detalle cada uno de ellos:

15 Sobre esta cuestión, resulta esencial: Martín Abad, Julián (2003): "Del ejemplar, o de ciertas historias (casi) siempre pasadas por alto", op. cit.

16 La aplicación de los criterios de conservación desarrollados por el equipo del Área Histórica obliga al aislamiento de aquellos ejemplares deteriorados en un espacio de cuarentena para acometer su restauración, y por razones de seguridad no pudieron ser consultados físicamente. Eso obligó a la extrapolación de la información obtenida en el análisis de libros que formaran parte de la misma obra, sostenida gracias a la información proveída por Breccia y Fugaro en su catálogo. Quedaron por tanto fuera de nuestro examen visual un total de 216 ejemplares, del total de 3.215 afectados por nuestro estudio.

17 Trabajo ya realizado por Breccia y Fuggaro, sobre el que este estudio se apoya continuamente (si bien ha requerido alguna corrección). 


\section{Edición}

Esta variable es la que habitualmente se emplea, casi en solitario, para recomponer las filiaciones entre los diferentes ejemplares de una colección. Ordena los libros en base a su lugar de impresión, puesto que se deduce, y en el caso de los libros estudiados tiende a ser así, que un título compuesto por varios ejemplares se compra completo, y tiende a provenir de un mismo origen, aunque los años de edición entre el primer y último volumen muestren un desfase. Pero esto no siempre es así, ya que existen casos en que el particular recompone el título u obra en base a originales de diferente procedencia, lo que obliga a la revisión del resto de variables para ver si existen conflictos de este tipo.

En nuestro caso, lo primero que revisamos fue el autor, de ahí que hayamos elegido un ordenamiento alfabético y no cronológico para la presentación de resultados en el informe. Tras ello, se comprueba cuántas obras existen del mismo y qué volúmenes constituyen cada una de ellas, revisando sus lugares y años de impresión. Con todo ello, muchas veces ya hemos recompuesto el título con los ejemplares que lo componen, pero es necesario revisarlos físicamente, para establecer que el resto de variables no presentan conflictos, es decir, que los libros que componen la obra han tenido un tránsito vital similar, o que han sido unificados en un momento dado, pero siempre con anterioridad a su llegada a la Biblioteca de la Universidad Central ${ }^{18}$.

Se ha de ser cuidadoso al tratar con las fechas de impresión, ya que es posible caer en el error de asumir que un determinado título estaba presente en la Real Audiencia de Quito o en la República del Ecuador en fechas cercanas a su impresión, cuando en absoluto tiene por qué ser así. Se requiere de una argumentación probatoria, ya sea porque tengamos constancia documental de su llegada, o porque se nos explicite un momento de traspaso entre propietarios locales. Esto quiere decir que por más que se encuentren libros incunables europeos, como los dos que contiene el fondo ${ }^{19}$, esto no implica que ya circularan por la Real Audiencia de Quito en el siglo XVI, o que si tenemos un libro de Newton como las tres colecciones de la Biblioteca de la Universidad Central ${ }^{20}$, impresos a mediados del siglo XVIII, no podemos inferir que desde esa época se leía a Newton en la Real Audiencia de Quito. Dependerá de las pautas de comercialización y circulación de los libros, y por tanto, necesitará un sólido apoyo documental para sostener que determinada obra estaba al alcance de los lectores quiteños.

También, teniendo en cuenta la información que nos brindan los libros, nos podemos apoyar en las marcas de propiedad para determinar un momento seguro en que un libro ha estado presente, si bien eso no implica que ya lo estuviera o no con anterioridad ${ }^{21}$.

Para poder sortear esta cuestión de alguna manera, y para simplificar la elaboración de los resultados, se ha establecido una división temporal en base a cuartos

18 No es extraño que una obra se haya formado antiguamente con ejemplares sueltos, de ahí que en determinadas ocasiones existe una marca de propiedad en algún volumen que no tienen el resto, pero el resto de elementos permiten discernir que llegaron ya unidas a la Biblioteca de la Universidad Central. En el caso de la Biblioteca de San Gregorio no es tan habitual ver propietarios en libros anteriores a su adquisición por los jesuitas.

19 AH 5328009 y AH 5328010.

20 AH 53 01205, AH 5301367 - 01377 - 01317 y AH 5301635 - 01645.

21 De ahí parte de la importancia de identificar a estos propietarios y ubicarlos en el tiempo. En el caso de la obra AH 5301635 - 01645, que también es de Newton, va firmada por Unanue. 
de siglo, de tal manera que se puedan percibir tendencias generales ante la imposibilidad de asumir la investigación documental requerida. Así los investigadores que lo deseen podrán encontrar un punto de partida sobre el que basarse al orientar sus estudios en la publicación del informe.

Igualmente, se ha sometido a las materias temáticas a un proceso de simplificación (si bien en las tablas por obra de los anexos se respeta el criterio de los italianos). Para ello se ha recurrido a las categorías básicas del sistema Dewey de clasificación, adaptándolas a nuestras necesidades. Así, junto a las propias del sistema (Arte, Ciencias Sociales, Filosofía y Psicología, Historia y Geografía, Lenguas, Literatura, Matemáticas y Ciencias Básicas, Religión y Tecnología y Ciencias aplicadas) se han añadido los criterios Derecho Civil, Derecho Canónico y Biografías; y eliminado Genéricos.

\section{Encuadernación}

En su mayoría, los libros analizados cuentan o bien con una cubierta de pergamino o bien con una de cuero. En muchos de los casos puede ser la única cubierta que tuvieron a lo largo de su vida ${ }^{22}$, en otros se tratará de reencuadernaciones, y por tanto, habremos perdido la información histórica que pudiera registrarse en la cubierta antigua.

Se decidió reflejar de manera básica si la encuadernación era de pergamino o de cuero, de tal manera que se pudieran percibir algunas tendencias generales en base a esta distinción. No obstante, se reconocieron algunos tipos de encuadernación en pergamino más habituales que otras, por lo que se decidió registrar cuando un ejemplar las tenía para comprender su funcionamiento (Per1, Per2, Per3 y Per4). Se buscaba con ello comenzar el trabajo de distinción entre técnicas de encuadernado en pergamino, dada la sospecha de la existencia de talleres de encuadernación en la Real Audiencia de Quito. No obstante, en los cuatro casos registrados se encuentran paralelos más allá de las bibliotecas históricas quiteñas. Eso obligará a la evaluación de otras cubiertas en pergamino para averiguar patrones de los que se pueda inferir la presencia de talleres locales, así como la revisión de documentación escrita de entidades capaces de sostener algo así, principalmente órdenes religiosas. Otro elemento elocuente en esta cuestión son los documentos que en ocasiones se usan como hoja de guarda: cartas, misales, partituras, etc., que puede resultar interesante recuperar no solo por su valor en sí, sino como elemento datante del propio taller de encuadernación ${ }^{23}$.

Pese a que no han sido un objeto preferencial de los investigadores, se conoce la existencia de talleres de encuadernación en algunos lugares de la antigua Colo-

$22 \mathrm{Y}$ es que un taller de impresión no implica necesariamente uno de encuadernación, por tanto, se ha de tener cautela a la hora de diferenciarlos. Sirva como ejemplo en el fondo la obra Sobrino aumentado, o nuevo diccionario de las lenguas española, francesa y latina, de Francisco Cormon (AH 5302158 - 02156 - 02157): en el primer volumen (AH 53 02158) encontramos el siguiente texto: "San Miguel, encuadernador, calle de la Carne $n^{\circ}$. 174 junto á la de S. Francisco. En Cádiz”, mientras que los libros fueron impresos en Amberes.

23 Como por ejemplo, la carta reciclada en AH 5321831. 
nia española en América ${ }^{24}$ incluyendo la Audiencia de Quito, donde ya ha habido quién las ha inferido en base a los comentarios del padre Cicala ${ }^{25}$.

\section{Alteración de cubiertas}

En algunas ocasiones, los propietarios de un fondo, ya fueran personajes privados o instituciones, deciden dar una homogeneidad visible a los tomos de su colección, habitualmente pintándolos en su parte exterior. En el caso de que la librería fuera de dimensiones considerables, como las de las grandes instituciones, se les da incluso un número de signatura que fuera perceptible sin necesidad de abrir el libro, y que nos permite identificar cuando dos libros que no comparten otros criterios han compartido estantería, y pensar en la distribución de las materias que se aplicaba en esas bibliotecas para ubicar sus ejemplares.

En este caso, la variabilidad en las alteraciones es profusa, obligando incluso a una codificación que la haga asequible. Por ejemplo, los numerosos libros pertenecientes a la Universidad San Gregorio fueron pintados de blanco en sus lomos, situación que codificamos como Pintado USG. Tenemos muchos más casos, a veces sólo afectando a un título formado por varios ejemplares, a veces amalgamando obras diferentes. En otras ocasiones, se dan dos capas de pintado, situación habitual en el caso de la Biblioteca Nacional "Eugenio Espejo", donde los libros provenientes de la Biblioteca del Colegio Máximo, ya pintados en tiempos de los jesuitas, fueron repintados en un momento posterior, indeterminado.

\section{Signaturas antiguas}

No me cansaré de insistir: la signatura topográfica, un dato (desgraciadamente tan) cambiante en la historia del ejemplar, dentro incluso de una misma biblioteca, tiene enorme importancia. El control de sus sucesivos cambios evitará un riesgo siempre latente: la creación de ejemplares imaginarios. Las bibliotecas históricas conservan (casi) siempre unas correspondencias de las signaturas que se anularon y de las nuevas. Las signaturas que ya no se utilizan para localizar el ejemplar, pero constan en él, deberán indicarse siempre en los catálogos de las bibliotecas y considero que útil hacerlo igualmente en los repertorios tipobibliográficos, por el simple hecho de que estuvieron en algún momento en uso y pueden haberse citado. No hay que olvidar que muchos de nuestros repertorios son antiguos y que debido a su buena factura o simplemente porque ninguno más moderno suple su consulta siguen siendo magníficos instrumentos de información ${ }^{26}$.

24 Aspell, Marcela, et al. (2000): La biblioteca jesuítica de la Universidad Nacional de Córdoba. Córdoba, UNC, p. 23; Parada, Alejandro E. (2009): "El libro de cargo y data de la Biblioteca Pública de Buenos Aires: Una breve descripción de las prácticas de gestión bibliotecaria (1810-1818)” en Casazza, Roberto (Coord.) Artes y Ciencias en la América Colonial: investigaciones presentadas en el simposio internacional homónimo realizado en Buenos Aires los días 23, 24 y 25 de noviembre de 2005. El libro de cargo y data de la Biblioteca Pública de Buenos Aires: Una breve descripción de las prácticas de gestión bibliotecaria (1810-1818). Buenos Aires, Teseo; 146-147

25 Fierro-Renoy, Juan Francisco (2008): “Las bibliotecas de la Compañía de Jesús...”, op. cit., p. 312.

26 Martín Abad, Julián (2003): “Del ejemplar, o de ciertas historias (casi) siempre pasadas por alto”, op. cit., p. 17. 
Como vemos en el extracto, contamos ante dos situaciones al registrar las signaturas antiguas que permanecen sobre los libros: que pertenecieran a fondos anteriores, o que respondan a antiguos ordenamientos de la propia biblioteca.

En el primer caso, encontrar signaturas antiguas nos sirve casi únicamente para filiar libros ${ }^{27}$, dado que no se suelen repetir en muchas obras. Sólo en el caso de los libros de la Biblioteca de la Universidad San Gregorio se podría realizar un análisis de las lógicas de ordenamiento de aquél centro, puesto que se conserva la mayor parte de sus obras y de localizarse los inventarios del mismo -que muy posiblemente estén en el Archivo Nacional del Ecuador- se podría realizar un interesante investigación en el contraste de ambas fuentes de información.

En el segundo, hemos detectado en los libros diferentes sistemas de signatura y codificación empleados por la Biblioteca Universitaria, lo que ha permitido, en conjunción con los sellos de propiedad que también se fueron sucediendo en el tiempo, adentrarnos en la evolución de los sistemas de gestión, adquisición, retirada de libros y creación de nuevas secciones de este repositorio.

\section{Marcas de propiedad}

Bajo el término "marcas de propiedad" se aglutinan una serie de elementos añadidos en diferentes partes del libro para identificar a su dueño. Entre ellos distinguimos:

- Textos de propiedad manuscritos:

Firmas: es una de las maneras más habituales de marcar propiedad, simplemente se firmaba en alguna parte de las primeras páginas del volumen. Se ha de estar atento al hecho de que pese a que consigamos desentrañar el nombre del firmante resulta necesario cotejar la firma con aquellos documentos que conozcamos firmados por esa persona para asegurarnos de que estamos identificándolo correctamente, ya que son habituales los casos de homonimia entre varios sujetos de diferentes momentos temporales.

Monogramas: No tan habitual en los libros del Fondo "Universidad Central del Ecuador 1485-1960" en su versión manuscrita.

Textos de propiedad: Cumpliendo la misma función que la firma, simplemente explicita algo más de información sobre el propietario, como títulos, año de adquisición, o incluso indicaciones topográficas ("Es de la libreria de la Universidad de san Gregorio fundada en el Colegio Maximo de la Compañia de Jesús de Quito"). En este apartado también contamos a los ex dono o texto de donación, que nos indica un traspaso de un propietario a otro. Muy habitual en la primera mitad del XIX, cuando los escolares de la Universidad de Quito estaban obligados a entregar libros a la biblioteca al recibir un grado universitario.

- Marcas de propiedad en sello de tinta: El empleo de sellos implica que el propietario dejó su marca en un momento tardío, es decir, que por lo que se ha ido viendo a lo largo de esta investigación, los sellos aparecen relacionados de manera general a personas vivas del siglo XIX en adelante, salvo alguna excepción que puede haberse dado y que no hayamos sabido identificar.

27 Por ejemplo, con los restos de la signatura del convento de los Franciscanos en Quito, ubicado en la parte superior de los lomos, de la que tenemos al menos dos ejemplos (AH 5300028 y 22116). 
Sellos figurativos (heráldicos, institucionales): Sellos que incluyen el emblema del propietario, y en ocasiones un refuerzo textual que nos ayuda a identificarlo.

Monogramas: Sellos que con tinta imprimen las iniciales que representan al propietario. Su interpretación es compleja dado que no suelen ser especialmente explícitos.

Textuales: Sellos en los cuales la información se despliega textualmente, lo cual permite identificar perfectamente al propietario, y en ocasiones van acompañados de información adicional como año de adquisición o signatura.

- Ex libris: Se trata de papeles o tiras adheridas al volumen, generalmente en la contratapa de la cubierta. No se dan muy habitualmente en el fondo.

Heráldicos: ex libris en que la marca de propiedad se indica en base al escudo nobiliar del propietario.

Textuales: En ellos la información sobre el propietario va explicitada textualmente.

No todos los que fueron propietarios de un volumen en un momento dado dejaron constancia de ello. Si un libro no muestra muchas firmas no quiere decir que no esté circulando, y perder de vista este hecho puede provocar errores de interpretación a la hora de reconstruir intercambios. Señalar la propiedad de un libro es una práctica bastante difundida ya desde el siglo XVII, como demuestran los ejemplares del Fondo "Universidad Central del Ecuador 1485-1960", matizando la afirmación de que las marcas de propiedad evidencian la relación más intensa entre libro y propietario desde la llegada de la Ilustración ${ }^{28}$. Es lógico que si el ejemplar ha entrado a formar parte de una biblioteca institucional, deje de circular por mucho tiempo, y por tanto sólo veamos firmas manuscritas antiguas (s. XVII por lo general cuando nos referimos al Fondo jesuita); pero en muchas ocasiones vemos muy pocos propietarios reflejados con firmas en libros que nunca han entrado en bibliotecas institucionales. Hemos de suponer por tanto que pasó de una biblioteca personal a la siguiente, ya fuera por intercambio en vida o a la muerte de su dueño, y no nos legaron constancia de ese hecho en el propio ejemplar.

Otro hecho a tener en cuenta es la diferencia entre una firma que evidencia propiedad de otra que sólo está especificando uso, siendo por lo general esta segunda la que se explicita (con la expresión "ad usum" o "del uso de").

Cuando el libro está firmado, el lugar en que habitualmente se suelen encontrar las marcas de propiedad es en las portadas, muchas veces también en el recto y en el verso de las hojas de guarda o de anteportada si el ejemplar las tiene. Ocasionalmente, las firmas aparecen tras la portada ${ }^{29}$, siendo dentro de estos casos muy habitual que la plasmaran inmediatamente tras el inde $x^{30}$ o al final del libro.

28 Keeding, Ekkehart (2005): Surge la nación..., op. cit., p. 260.

29 Como apunte para quienes busquen rastrear pautas de lectura de un volumen, resulta muy significativo el hecho de que en ocasiones un nuevo propietario ha tachado el nombre del anterior en la portada, pero no en las páginas interiores, lo que seguramente esté señalando que no se leyó muy detenidamente el libro y no se dio cuenta de ese detalle, puesto que lo normal habría sido tachar igualmente esas firmas interiores.

30 Muy habitual con los textos de propiedad de la Universidad San Gregorio. 
Era bastante común tachar, sobrescribir o borrar (incluso con productos) las marcas de propiedad de sus anteriores dueños. En muchos casos un buen proceso de restauración podría ser capaz de recuperar esta información, detectando incluso firmas o textos hoy día invisibles, pero cuya impronta queda grabada en las páginas de los libros.

En los libros antiguos del Fondo "Universidad Central del Ecuador 1845-1960" se percibe un patrón claro, por el cual varias obras de una colección pasan en bloque de propietario a propietario, llegando reunidas a la Biblioteca universitaria. Se pueden rastrear, como es el caso de la colección de trece volúmenes de las obras de Edmonde Martène ${ }^{31}$, cómo ésta ha pasado por tres propietarios en diferentes momentos.

Si bien nos hemos centrado en el rastreo de estas marcas de antiguos poseedores, tendencia cada vez más común en las bibliotecas europeas y norteamericanas $^{32}$, ello no quita para destacar que junto a estos datos existen muchos otros escritos sobre precios, librerías o pequeñas anotaciones de los lectores cuyo análisis puede resultar muy interesante en el futuro. No entramos, por no ser el objeto de nuestro estudio, en cuestiones de alto interés como el análisis de las pautas de lectura $^{33}$ (recordemos que poseer un libro no implica leerlo y viceversa, lo cual requiere un análisis muy diferente al nuestro), pero sin duda el fondo "Universidad Central del Ecuador 1485-1960” ofrece material suficiente para acometer esta labor.

\section{Resultados de la investigación}

Con toda la información proveniente de los libros reunida y trabajada, puesta en contraste con la documentación escrita y con la bibliografía específica, se pudieron comenzar a obtener los resultados pretendidos.

\section{Historia de la Biblioteca de la Universidad Central}

Ya hemos tenido ocasión de señalar la falta de información documental e historiográfica existente en lo que refiere a la historia de la Biblioteca de la Universidad Central. No obstante, nuestro trabajo pudo comenzar a desvelar algunos de los entresijos de su pasado.

Este repositorio nace en tiempos de la Universidad Pública Santo Tomás de Aquino, antecesora de la Central. Aunque no sabemos exactamente cuándo se crea la librería, queda constatada su existencia en documentos de los últimos años de la Colonia, cuando aquella universidad se ha hecho propietaria de la Biblioteca de la

31 AH 5300738 - 02058 - 00740 - 00739 - 00741 y AH 5300911 - 00914 - 03588 - 00831 - 00965 00966 - $00970-00969$.

32 Sirva como ejemplo el proyecto “Antics posseïdors" que desarrolla actualmente la biblioteca de la Universidad de Barcelona (que conserva un total de 150.000 volúmenes, la segunda colección en tamaño del España, solo por detrás de la Biblioteca Nacional), consultable en http://www.bib.ub.edu/fileadmin/ posseidors/home spa.htm, [Última consulta: 30-06-2015]. y al que se hace referencia en el siguiente artículo: Astals, Isabel, et al. (2010): "La base de datos Antics posseïdors de la Biblioteca de Reserva de la Universitat de Barcelona”, en BiD: textos universitaris de biblioteconomia i documentació, No. 24, s. p. <http://bid.ub.edu/24/astals2.htm> [Última consulta: 30-06-2015].

33 Molekamp, F.: "Using a collection to discover reading practices: The British Library Geneva Bibles and a history of their early modern readers". Electronic British Library Journal, article 10 (2006). http://www.bl.uk/eblj/2006articles/article10.html [Última consulta: 28-04-2015]. 
Universidad San Gregorio, que previamente había formado parte del fondo inicial de la Biblioteca Pública ${ }^{34}$. Por tanto, su fundación se ubicaría entre 1793, fecha de creación de la Biblioteca Pública, y 1810, que es cuando tenemos la primera noticia de que la Universidad Pública posee los libros de la antigua Universidad San Gregorio ${ }^{35}$.

Existen varios documentos más de finales de la Colonia que nos van indicando, directa e indirectamente, algunos avatares de la misma, como otras transferencias de libros desde la Biblioteca Pública ${ }^{36}$, sobre su mal estado de conservación ${ }^{37}$ o por conflictos entre los bibliotecarios públicos y los rectores de la Universidad, a causa de los espacios empleados en el Caserón universitario ${ }^{38}$.

Tras el proceso de Independencia, la Universidad Santo Tomás se convertirá, como sabemos, en la Universidad Central del Ecuador. Con ello llega un cambio en los estudios, lo que tiene el reflejo en las adquisiciones que se buscarán hacer desde entonces.

La documentación nos ha testimoniado al menos cinco fórmulas empleadas por la Universidad para conseguir nuevos libros durante la primera mitad del siglo $\mathrm{XIX}^{39}$ :

1. la venta de duplicados, que generaba ingresos para adquirir nuevas obras (vía explotada ya en las dos primeras décadas de esa centuria);

2. la adquisición de obras específicas a cambio de otros libros de la Biblioteca, para lo cual se podía encomendar la gestión a terceros;

3. la adquisición de obras específicas con fondos de la Biblioteca, alimenta dos por la obligación de que los alumnos dieran dinero a este efecto;

4. la recepción de donaciones voluntarias puntuales;

5. a recepción de donaciones obligatorias, impuesta a los alumnos de la Universidad.

Gracias a algunas noticias que nos va dejando la revista Anales de la Universidad Centrat $^{40}$ (fundada en 1883), sabemos que la Biblioteca Universitaria va a seguir

34 Acta de entrega de la Biblioteca a Eugenio Espejo transcrita en Vásquez Hahn, María Antonieta (2005), op. cit., pp. 151-155.

35 Sabemos que eran de propiedad de la Universidad porque el Claustro se reúne para decidir la venta de duplicados. AGUCE, Libro de acuerdos y claustros de ordenanza de la Universidad del Angélico Doctor Santo Tomás conforme a lo prevenido por sus constituciones, p. 273, "Acta del Claustro Universitario de 23 de mayo de 1810"; de 23/05/1810.

36 AGUCE, Documentos históricos y otros escritos 1821 - 1844, "Expediente sobre responsabilidad de J. F. Salvador en su gestión de la Biblioteca Pública entre 1796 y 1808”; de 06/06/1844.

37 ACM, Colección González Suárez, Caja 7, p. 15, doc. 4, "Oficio del Bo P. J. Pérez al Pres. de la Audiencia"; s. f. [1810-1817].

38 ACM, Colección González Suárez, Caja 7, p. 16, doc. 5, “Oficio del Bo P. J. Pérez a J. Ramírez Orozco, Pres. de la Aud.”; s.f. [1816-1819].

39 Todas ellas documentadas tanto por textos escritos como por información extraída de anotaciones en los propios libros, datos que serán publicados en el informe.

40 Números 4 (1883 Junio), pp. 197-204; 111 (1902 Enero), pp. 371-378; 113 (1902 Marzo), pp. 527-532; 115 (1902 Mayo), pp. 181-187; 128 (1903 Junio), pp. 228-235; 37-39 (1915 OctubreDiciembre), pp. 146-153; 40-42 (1916 Enero-Marzo), pp. 250-254; 302 (1937 Octubre-Diciembre), pp. 599-603 y 275 (1931 Enero-Marzo), pp. 114-181. 
creciendo en los años siguientes, manteniendo una vida normal y haciendo las compras y canjes que va necesitando para mantener unos fondos adecuados a las necesidades de sus alumnos (en determinados números la revista informa incluso de qué obras se han adquirido, incluyendo ocasionalmente resúmenes de las mismas, justificando el interés de su compra y anunciando su disponibilidad a los estudiantes ${ }^{41}$ ). Con el tiempo pasaría a llamarse Biblioteca General, seguramente para diferenciarla de las que las propias facultades fueron creando ya desde la segunda mitad del siglo XIX ${ }^{42}$ (y cuyos libros han ido a parar, una vez descartados, a engrosar el fondo "Universidad Central del Ecuador 1485-1960").

Se fueron desarrollando diferentes métodos de administración de sus fondos: creación de secciones concretas (Jurisprudencia, Medicina, etc.), signaturas, sellos de compra y de propiedad, inventarios, distribución de libros por materias, autores, etc. Como veremos, sus libros testimonian perfectamente la historia tanto de la Biblioteca General como de la propia Universidad Central, puesto que van reflejando qué estudios se cursaban en cada momento y cuáles paulatinamente fueron suprimiéndose, lo que se traduce en un aumento o descenso de ejemplares de aquellas temáticas ${ }^{43}$.

Físicamente la Biblioteca Universitaria fue trasladada a la nueva sede de la Universidad Central, en su actual ubicación, a mediados del siglo XX. Previamente había sobrevivido al pavoroso incendio del Caserón universitario de $1929^{44}$, y atravesado una gran reforma de sus contenidos, que no sería la última, puesto que los sellos registrados en los libros demuestran la creación de varias secciones, entre ellas una antigua ${ }^{45}$.

\section{Sellos y signaturas antiguos de la Biblioteca General}

Todos los libros contenidos en el fondo "Universidad Central del Ecuador" muestran algún tipo de signatura o sello, varios de ellos, responden a los diferentes momentos en la gestión de la Biblioteca General.

De entre las signaturas ${ }^{46}$, la más antigua $(\mathrm{Sg} 2)$ consistía en un simple número ascendente, pintado en tinta negra sobre el lomo del primer libro de una obra, y que por cierto no se aplicó a ninguno de los libros de la Biblioteca de la Universidad San Gregorio. Puede pertenecer al siglo XIX o a los primeros compases del siglo XX.

41 Incluso inventarios parciales como el catálogo publicado en Anales en 1902 y el de Espín Lastra, Alfonso (1963): Libros coloniales de la Universidad de Quito ..., op. cit.

42 La marca de propiedad más antigua que hemos encontrado referente a bibliotecas particulares de facultades de la UCE. es el sello del Instituto de Ciencias y Escuela de Agricultura de Quito, creado en 1879 .

43 Es claro en el caso de los libros de teología, pues según estos estudios van desapareciendo los libros específicos, dejan de formar parte del repositorio de consulta, lo que evidencian los sellos empleados por los bibliotecarios, a falta de inventarios que solventen esta cuestión.

44 Orejuela, Manuel (1931 Enero-Marzo): "Boletín de la Biblioteca de la Universidad Central", en Anales de la Universidad Central, No. 275, pp. 115-121.

45 De la que se hace mención en Barrera, Jaime (1937 Octubre-Diciembre): "La Biblioteca de la Universidad", op. cit., p. 601.

46 Tipologías incluidas al final del artículo. 
Tras ella, aparecen dos signaturas simultáneas (EtR y EtA), en adhesivos pegados en la parte inferior del lomo de los libros. EtR, de color rojo y solamente cuando la signatura está mecanografiada, se aplica a todos los volúmenes y parece estar empleándose para los más antiguos, es decir, quizá los que ya están siendo separados para su protección. EtA se aplica de nuevo sólo al primer ejemplar de un título, siendo generalmente de color azul, pero también se emplean rojas -escritas a mano- y blancas. Consideramos que esta codificación pudo darse al trasladarse los libros al nuevo campus universitario, pero pudiera no ser exactamente así. En todo caso, debe corresponder a mediados de siglo XX.

Por último, tenemos los diferentes elementos aplicados para el inventario realizado en 1964, que sólo se aplicó a los libros que debían permanecer en consulta en la Biblioteca en aquel momento. Son etiquetas con un número simple en la parte inferior de los lomos, compartiendo cifra todos los ejemplares de una obra. En el interior se corresponde con varios sellos tanto en el canto de los libros como en sus primeras páginas. Este sistema se empleó desde entonces para los libros de nueva adquisición, distinguibles porque en ese caso se consigna la fecha de adquisición, en vez de escribirse "Inv" (inventario), en el interior del ejemplar.

Por otro lado, existen en torno a 6 sellos diferentes, 2 de ellos relacionados con la fase de inventario recién mencionada (SeCir1 y SeCir2), y otros anteriores, cuyo uso en el tiempo tiene que ver con las fases de adquisición de la Biblioteca, pero no se pudo trabajar más en ese sentido ${ }^{47}$.

\section{Los libros antiguos del Fondo "Universidad Central del Ecuador", resultados de la investigación}

En términos generales, se ha discernido la existencia de dos elementos separados: los libros que conformaron la Biblioteca de la Universidad San Gregorio y el repositorio que fue generando la propia Biblioteca Universitaria o General aparte de esta dotación inicial. Se han tratado por separado para respetar la personalidad de la primera.

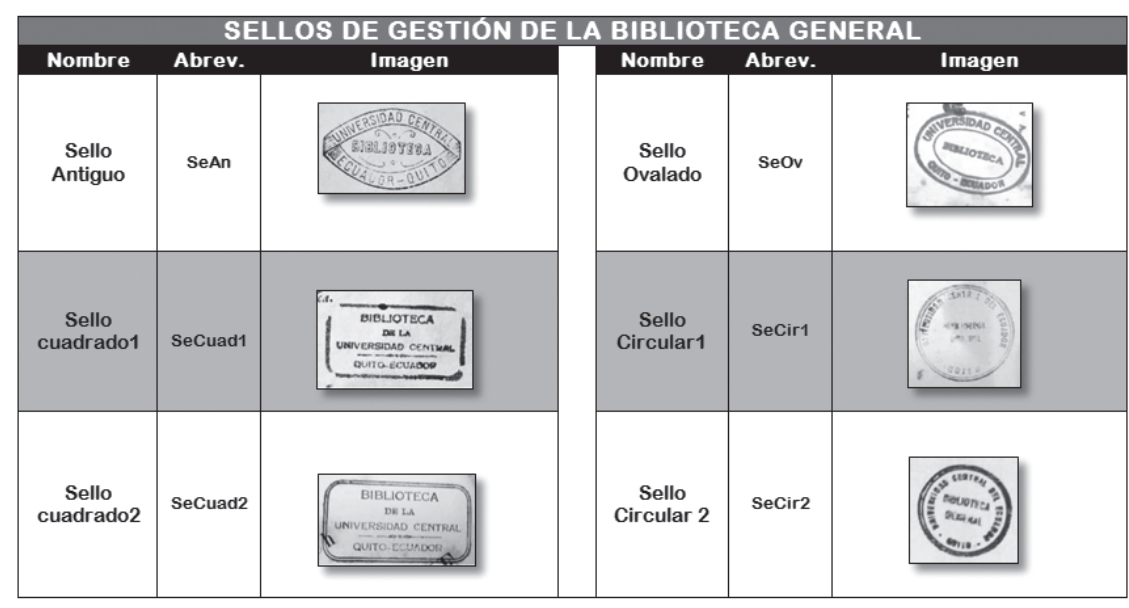

47 De contrastarse con el resto de libros del fondo, se podría establecer periodos de uso de cada uno, haciendo cateos aleatorios con muestra significativa por décadas, revisando también libros que, gracias a las publicaciones de la revista Anales, sabemos cuándo ingresaron a la Biblioteca General. 


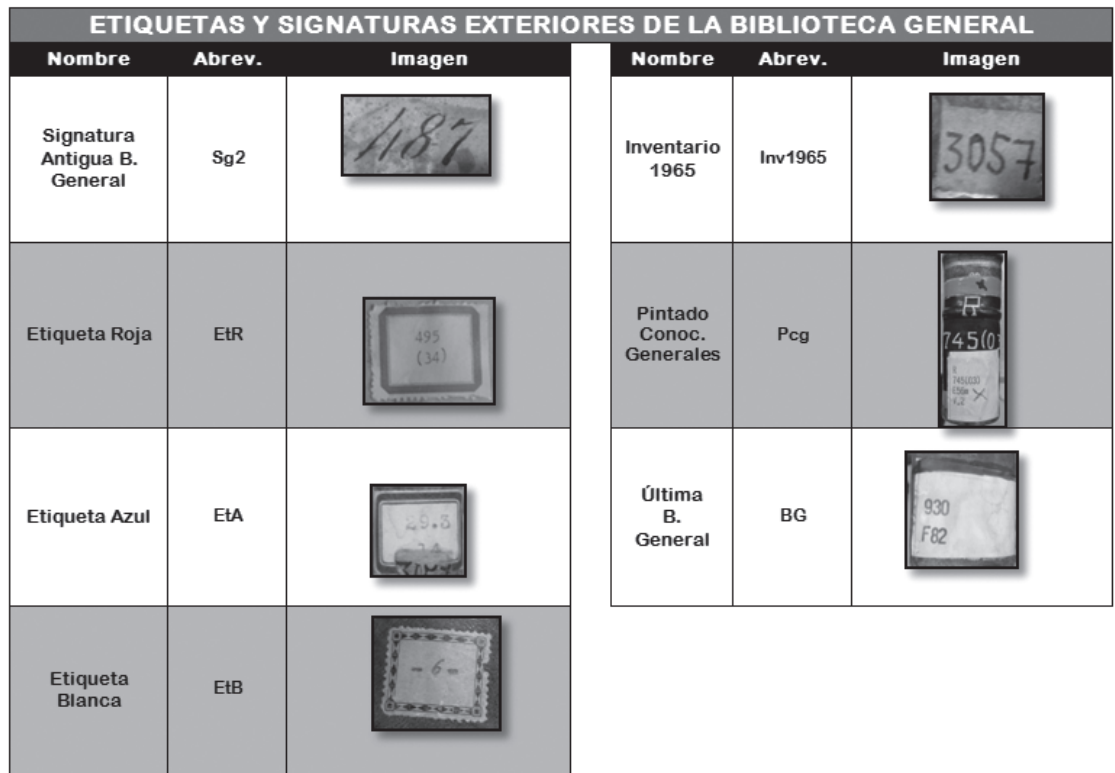

\section{Biblioteca de la Universidad San Gregorio}

Ha quedado ya establecido que esta biblioteca llegó a custodia de la Universidad Pública Santo Tomás de Aquino previo paso por la Biblioteca Pública, y de ahí a la Universidad Central. Hoy día se conservan en el Fondo "Universidad Central del Ecuador 1485-1960" un total de 566 volúmenes de este repositorio, de los $826^{48}$ que Eugenio Espejo en su inventario inicial de la Biblioteca Pública dio por recibidos. Se ha de hacer notar que los manuscritos y los tres inventarios nunca llegaron a la Universidad (seguramente no salieron de la Biblioteca Pública, y acabaron pasando al Archivo Nacional del Ecuador a finales del siglo XX, donde se encuentran hoy día), y si añadimos la venta de duplicados antes mencionada, así como los avatares lógicos del paso del tiempo, podemos considerar que la UCE conserva lo que queda unido de la Biblioteca de la Universidad San Gregorio. Son 333 títulos entre obras completas e incompletas ${ }^{49}$.

Estos libros se reconocen fácilmente por tres de las variables manejadas en nuestro análisis: alteración de lomo (están pintados de blanco), signatura antigua (superpuesta en los lomos en tinta negra, con una numeración de bloque en la parte superior y otra individual en la inferior) y marcas de propiedad (pocas veces no está presente, suele ser un texto de propiedad manuscrito en el que, con variaciones, se indica la propiedad de la Universidad San Gregorio). Existen otros

48 En el momento del secuestro las autoridades de la Audiencia contabilizaron 804 libros. Inventario de la Universidad San Gregorio de la Compañia de Jesús durante su secuestro en 1767. Transcripción del P. Francisco Piñas Rubio, Julio de 2008, p. 12. Consultable en:

http://www.cervantesvirtual.com/obra/testimonio-del-sequestro-del-colegio-de-s-luys-y-universidad-de-s-gregorio/ [última consulta 25/04/2015]

49 Esto supone una manifestación de la revisión del trabajo de Breccia y Fugaro, quienes reducían esta cantidad en su base de datos a 322. A ello añadirían dos obras que se encuentran en la Biblioteca Aurelio Espinosa Pólit, según los mismos investigadores. 
ejemplares repartidos por bibliotecas históricas y privadas, pero queda patente que su reconocimiento visual es sencillo.

El interés de su estudio radica en que se trata de un repositorio que fue armándose en el tiempo con libros contemporáneos, y además, quedó cerrado a la expulsión de la Compañía de Jesús. Las lógicas que explican su formación pueden entenderse en las tendencias que marcan los libros según fechas, aunque como ya se ha avisado, más como sugerencia que como realidad, por cuanto sin inventarios realizados en diferentes momentos no podemos saber cuándo estaban llegando los libros a la Biblioteca de la Universidad. Lógicamente, en ningún caso se encuentra un libro impreso con posterioridad a $1767^{50}$.

Analizando las fechas de edición de los libros conservados, se detecta un claro aumento en a inicios del siglo XVII, con un descenso a final de esta centuria que se recupera progresivamente en la primera mitad del XVIII, tendencia truncada por el cierre de la Universidad San Gregorio en 1767.

En lo referente a autores, hemos podido contabilizar 305 autores diferentes, entre los que destacan Martín de Esparza Artieda con 10 títulos ${ }^{51}$, Manuel de Nájera con siete y Paolo Segneri con seis.

Los centros de impresión con mayor representación en la Biblioteca de la Universidad Central son Madrid (124 libros), Londres (88), Venecia (58) y Amberes (42). Los libros procedentes de Madrid se reparten en el tiempo, sin concentrarse relativamente al resto en ningún tramo, mientras que los de Londres, pese a que siguen la tendencia general del siglo XVII, desaparecen para el XVIII. Los libros impresos en Venecia tienen un auge temprano a fines de siglo XVI (algo similar a lo acontecido en la Biblioteca de la UCE) pero su presencia es testimonial a lo largo del siglo XVII, recuperándose notablemente en la primera mitad del siglo XVIII. Por último, los libros editados en Amberes siguen la tendencia general para el siglo XVII, si bien nunca aumentan su presencia en el siglo XVIII.

Por materias, Religión es la que más obras acoge (69,97\% del total), debido, como ya hemos tenido ocasión de resaltar, al espíritu de las universidades religiosas y el ambiente contrarreformista que sólo comenzó a abrirse desde mediados del siglo XVIII, de manera tímida, por la llegada de ideas ilustradas europeas. Se cuenta igualmente un buen número de obras de Derecho Canónico, Filosofía (tengamos en cuenta que las obras de Teología caen en el apartado de Religión) Biografías y Geografía e Historia. En menor grado, existen obras sobre Literatura, Ciencias Sociales, alguna sobre Matemáticas y Ciencias Básicas y Tecnología y Ciencias Aplicadas (estas últimas llegadas a inicios del siglo XVIII).

En lo tocante a encuadernaciones, en números totales el pergamino es preponderante (92,05\% del total), si bien se percibe, al igual que en el caso de la Biblioteca Universitaria, un aumento de la presencia de la encuadernación en cuero desde mediados del siglo XVII.

50 La fecha de impresión más moderna registrada es de 1752, referente a los ejemplares AH 5301584 y AH 53 01501. Por cierto, ambos publicados en México.

51 Quizá esté sobrerrepresentado ya que cada una de sus Quaestiones disputandae se tomó como una obra individual, mientras que se podría haber considerado como una sola, lo que no lo habría hecho destacar sobre el resto. 
Ya hemos comentado la alteración de cubiertas y la existencia de una signatura propia de esta Biblioteca que se ha conservado hasta nuestros días.

En lo que refiere a las marcas de propiedad que no son las de la propia Universidad gregoriana, se han contabilizado 35 firmas legibles diferentes de antiguos propietarios, entre las referentes a instituciones (otros centros de enseñanza jesuitas, 22 ocasiones) y a personas individuales (33 personas individuales, que no se suelen repetir). Evidentemente, el tránsito del libro acabó ahí, hasta pasar a manos de la Universidad ${ }^{52}$.

\section{Biblioteca de la Universidad Central}

El fondo generado por la Universidad Central para su propia biblioteca, nacida como sabemos a principios del siglo XIX, asciende en sus libros antiguos (anteriores al 1 de enero de 1801) a un total de 1.082 títulos en 2.649 volúmenes. Es tan sólo una pequeña fracción de la totalidad de los libros que esta biblioteca fue concentrando en sus dos siglos de historia. Dado que los libros estudiados son anteriores a la creación del propio repositorio, su lógica de concentración es un tanto aleatoria: la muestra está condicionada tanto por las donaciones voluntarias, cuyo contenido no era controlable, como por la capacidad de la Universidad de obtener libros, ya que resulta plausible pensar que preferentemente se dirigieron al mercado local ${ }^{53}$. La lectura de los datos obtenidos al estudiar las materias abarcadas por los libros antiguos de esta Biblioteca no son comparables a los de la Biblioteca de San Gregorio, que era contemporánea a los libros que adquiría, y por tanto si se pueden interpretar lógicas de adquisición en base al currículum educativo de aquella universidad y su evolución en su más de siglo y medio de existencia.

Temporalmente, el mayor número de obras pertenecen al siglo XVIII, aumentando según nos acercamos al XIX. Esto es lógico, por cuanto la Universidad preferirá adquirir obras más modernas más actualizadas y de temáticas que respondan a la renovación de estudios atravesada desde finales del siglo XVIII.

Hemos encontrado la presencia de 633 autores diferentes, teniendo en cuenta que se han separado las obras de autoría individual de las colectivas que compartan un mismo autor, y que existen 117 obras consideradas sin autor (S. A.). Destacan autores como Ovidio, con 8 obras; Santo Tomás de Aquino con 9, Cicerón con 10 y Agustín Barbosa con 15.

Las obras de la Biblioteca de la UCE provienen de muchas imprentas europeas, y también algunas americanas, incluyendo México, Puebla, Lima, e incluso un ejemplar editado en Quito en $1780^{54}$. Las imprentas más representadas son

52 En la publicación del informe aparecen las listas de propietarios y las obras en que aparecen, por lo que no redundaremos en ello aquí.

53 Aunque sepamos que en determinados momentos se delegó en algunos personajes, expertos en la compra-venta de libros, para que adquieran nuevos ejemplares en otros lugares, es el caso de la gestión llevada a cabo por Henri Ternaux-Campans (1807-1864): AGUCE, Libro de Juntas de Gobierno. Años 1835 a 1839, p. 83, "Acta de la Junta de Gobierno Univ. de 5 de febrero 1838"; de 05/02/1838.

54 Se trata de la obra en un solo volumen Satisfacción legal del Dr. d. Nicolás Pastrana y Monteserín, cura proprio del pueblo de San Pedro de Conocoto en el obispado de Quito, contra la alegación jurídica, que dio al público el bachiller don Francisco Xavier de la Fita y Carrión (AH 53 02518). 
Madrid (842 libros), París (628), Venecia (252), Londres (126), grandes capitales europeas y potencias en la impresión de libros. Evidentemente Madrid destaca sobre todas ellas por cuanto es la capital de la metrópoli. Mientas que los libros procedentes de esta villa muestran una presencia continuada en el tiempo, los de Londres decaen a mediados del XVIII, precisamente cuando se ve un aumento de los parisinos.

Los cuatro centros productores mantienen una presencia relativamente estable frente al resto (salvo el aumento de obras procedentes de Venecia en el último cuarto del siglo XVI), con un aumento generalizado a principios del siglo XVIII. Mientras que el número de obras producidas en Londres decae a mediados de la centuria para no recuperarse; la de Venecia, con mayor representación, también desciende en ese momento pero en un ritmo menor. París muestra un ascenso muy marcado que sólo se frena, manteniéndose, desde el tercer cuarto del siglo; y Madrid, cuya presencia siempre es acusada en comparación con el resto de imprentas, claramente se desmarca del resto en el tercer cuarto del siglo XVIII.

Religión es la materia, de nuevo, más representada entre los libros antiguos, seguida por Geografía e Historia. No obstante, los libros que versan sobre Ciencias Básicas y Aplicadas van en aumento desde el segundo cuarto del siglo XVIII, demostrando cómo la llegada de la Ilustración se hace presente.

En lo tocante a las encuadernaciones, tenemos 969 libros en pergamino y 1663 en cuero, con un aumento relativo de los segundos desde mitad del siglo XVII, al igual que se veía en los libros de la Universidad San Gregorio.

Se han detectado algunas signaturas antiguas, relativas a otros repositorios, como las del Convento de San Francisco o las del Colegio jesuita de Riobamba.

En cuanto a propietarios, se han contabilizado 332 propietarios distintos para un total de 585 obras marcadas. 19 de ellos de instituciones y el resto de particulares. Destacan instituciones religiosas, sobre todo jesuitas, aunque también del Convento de San Francisco y de la Recolección de la Merced, en Quito.

\section{Encuadernaciones en pergamino especiales}

Señalábamos que se habían identificado cuatro tipos de encuadernaciones en pergamino concretas, y que se hizo un seguimiento para ver cómo respondían al resto de variables analizadas y poder arrojar algo de luz sobre ellas. Todos ellos aparecen en libros de ambas bibliotecas, por lo cual los talleres no son de ninguna. De hecho, hemos llegado a la conclusión de que estas encuadernaciones provienen de Europa, dado el origen de los libros y la inexistencia de datos que apoyen otra línea de interpretación:

Per1: existen 359 ejemplares, impresos todos entre 1596 y 1791, el 55,15\% en Madrid, el 21,45\% en Venecia, y el resto en diferentes lugares de Europa, y 4 de México, lo que ubica alguno de los talleres que encuadernaran según este estilo en suelo americano.

Per2: existen 120 libros, impresos entre 1627 y 1770, el 48\% en Madrid, el 28 $\%$ en Venecia y el resto en diversas imprentas europeas. 
Per3: 56 libros, impresos entre 1709 y 1772, siendo el 78,57\% libros editados en Italia (55, 35\% del total en Venecia, $14,29 \%$ de Lucca) y el resto en ciudades alemanas o austríacas, además de uno en París.

Per4: 41 libros, impresos entre 1659 y 1758, siendo el 75,60\% de ciudades italianas y el resto de diferentes talleres europeos.

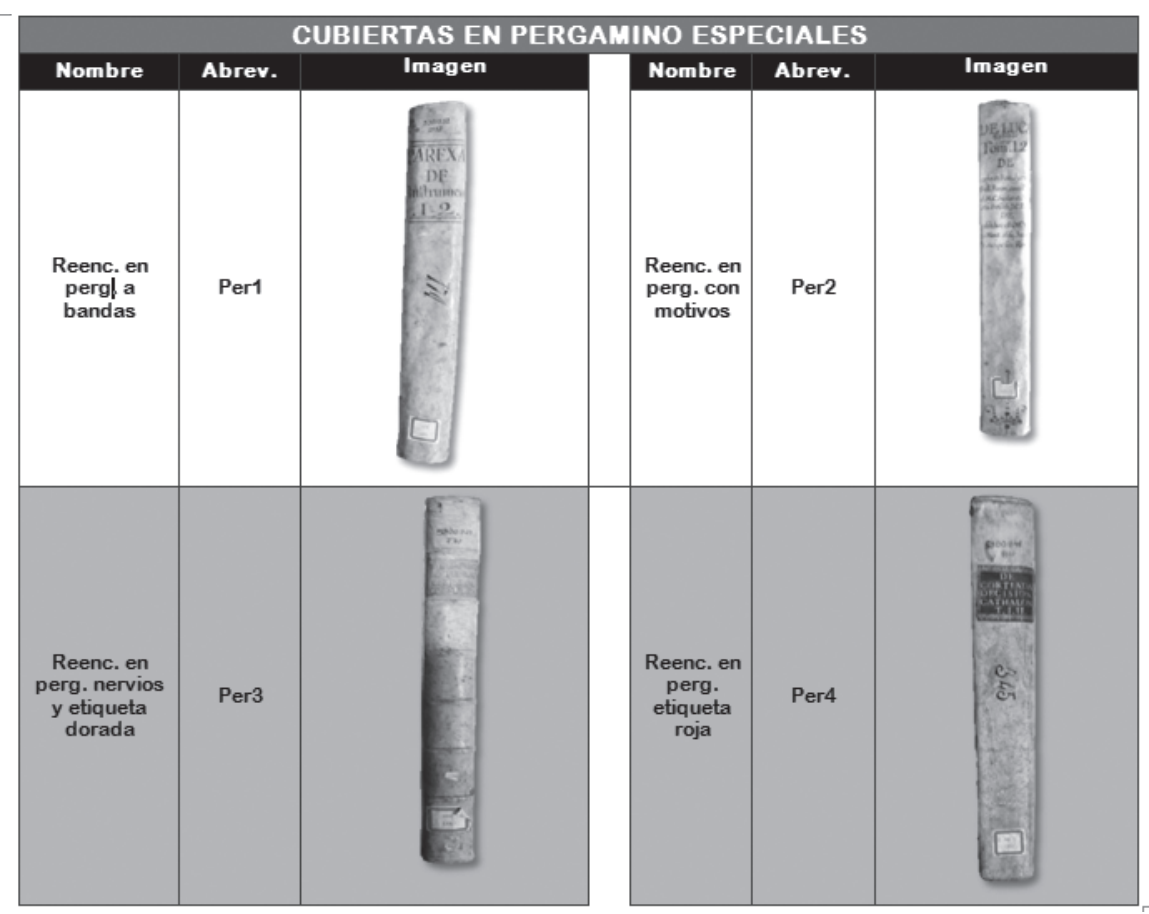

\section{Colecciones antiguas representativas}

Gracias a las filiaciones establecidas en la recolección de datos, pudimos establecer la existencia de varias colecciones, algunas numerosas, otras de tan sólo dos títulos.

Las más representativas han sido identificadas gracias a las marcas de propiedad dejadas por sus antiguos dueños. Así, encontramos 11 títulos en 25 ejemplares que pertenecieron a Eugenio Espejo, 14 títulos en 23 ejemplares del obispo Calama, 14 títulos en 21 ejemplares con el sello identificado como "Javier" y 25 títulos en 38 ejemplares de Carlos Andrés Casares. Junto a ellas, tenemos las 11 obras en 20 volúmenes que fueron de la Recolección de la Merced o las 6 del convento de los Franciscanos, ambos de Quito.

Otra colección ha sido detectada por tener los lomos pintados de verde (codificado como PinVer), formada por 3 obras en 13 volúmenes, sin que el resto de variables hayan aportado datos fiables sobre su propietario.

55 Entre los libros con este sello encontramos los dos incunables que conserva el fondo histórico, por lo que suponemos que era una colección de bastante relevancia. 
Destaca igualmente la presencia de obras que pertenecieron al Fondo Jesuita. Dejando los libros de la Universidad San Gregorio, que también son considerados parte del mismo, tenemos 24 obras en 71 volúmenes que fueron del Colegio Máximo en algún momento, 7 títulos en 8 volúmenes del Noviciado de Quito, 4 obras en 4 tomos del Colegio Seminario de San Luis, 8 títulos en 16 libros del Colegio de Riobamba, 6 títulos en 7 libros del de Latacunga, 1 obra en 4 tomos del de Pasto, 1 libro del Colegio Máximo de San Pablo de Lima y 1 obra en 2 tomos del Colegio de Panamá.

Por tanto, esta colección se compone de los 566 volúmenes de la Biblioteca San Gregorio y de 113 de la Biblioteca de la UCE, alcanzando un total de 679 libros.

\section{Conclusiones}

Pese a que en este artículo no se pueden desplegar los apartados empíricos que sostienen las conclusiones alcanzadas, ya que estamos hablando de decenas de tablas y gráficos, el lector quizá haya podido vislumbrar la utilidad del método propuesto. Caminar hacia la generación de tipologías de las diferentes variables de análisis empleadas aquí (que se espera se complejicen en futuros estudios) permite crear consensos, de los que con el tiempo nazca una estratificación común de fases en el tránsito vital de los libros, que es lo mismo que decir el establecimiento de colecciones antiguas por las que los ejemplares fueron pasando, y cómo podemos reconocer sobre los libros cada una de ellas. Con estos datos lo que hacemos es generar una sólida base de información sobre la cual los historiadores del libro y de la cultura en general puedan trabajar más fácilmente, evitando los agujeros dejados por la documentación escrita o los casos en que esta resulte poco fiable.

\section{Bibliografía}

Barrera, Jaime (1937, Octubre-Diciembre). La Biblioteca de la Universidad. En Anales de la Universidad Central, No. 302, pp. 599-603.

Espín Lastra, Alfonso (1963). Libros coloniales de la Universidad de Quito. Catálogo General. Quito: Editorial Universitaria.

Espinoza, Jaime (1931 Enero-Marzo). "La Universidad Central en los primeros cien años de vida republicana":

I, en Anales de la Universidad Central, No. 275, Apéndice.

II, en Anales de la Universidad Central, No. 276, Apéndice.

III, en Anales de la Universidad Central, No. 277, Apéndice.

Fierro-Renoy, Juan Francisco (2008). Las bibliotecas de la Compañía de Jesús en la Real Audiencia de Quito. En Naranjo, Plutarco y Fierro-Benítez, Rodrigo (eds.): Eugenio Espejo: Su época y su pensamiento. Las bibliotecas de la Compañia de 
Jesús en la Real Audiencia de Quito. Quito: Corporación Editora Nacional, pp. 303-321.

García Aguilar, María Idalia (2007). Libros marcados con fuego. En Emblemata, No. 13, pp. 271-299.

González González, Enrique (2013). Las universidades hispanoamericanas al filo de la Independencia en 1810. La insurgencia de América. Congreso Internacional Reunido en Valencia, 22-27 de marzo de 2010. Las universidades hispanoamericanas al filo de la Independencia. Valencia: Universitat de València, pp. 149-168.

Herrera, Pablo (1883 abril). Reseña Histórica de la Universidad de Quito: primera parte. En Anales de la Universidad Central, No. 2, pp. 57-60.

continuación, en Anales de la Universidad Central, No. 3, pp. 105-106.

continuación, en Anales de la Universidad Central, No. 5, pp. 219-221.

Jouanen, José (1941. Historia de la Compañia de Jesús en la Provincia de Quito. Quito: Ecuatoriana Plaza.

Jouanen, José (2003). Historia de la Compañia de Jesús en la República del Ecuador 1850 1950. Quito, EC.

Keeding, Ekkehart (2005). Surge la nación: la Ilustración en la Audiencia de Quito. 1725 1872. Quito: Banco Central del Ecuador.

Lozano Cabrera, M. (1950 octubre. Origen y desarrollo de la universidad ecuatoriana. En Revista de Filosofía, Letras y Ciencias de la Educación, año 3, No. 8, pp. 49-74.

Lucena Salmoral, Manuel (1999). El reformismo despotista en la Universidad de Quito. En Cuadernos del Instituto Antonio de Nebrija, No. 2, pp. 59-82.

Martín Abad, Julián (2003). Del ejemplar, o de ciertas historias (casi) siempre pasadas por alto. En Docampo Capilla, Javier (Ed.), Jornadas sobre Patrimonio Bibliográfico en Castilla La Mancha: actas: 12, 13 y 14 de noviembre, Alcázar de Toledo. Del ejemplar, o de ciertas historias (casi) siempre pasadas por alto. Toledo, Junta de Comunidades de Castilla-La Mancha, pp. 15-38.

Mena Mena, Camilo (1980). La Universidad: cultura en 150 años de Vida Republicana. En Luis Mora Ortega (coord.), Arte y Cultura. Ecuador: 1830-1980. La Universidad: cultura en 150 años de Vida Republicana. Quito: Corporación Editora Nacional, pp. 117-129.

Moncayo De Monge, Germania (1944). La Universidad de Quito en tres siglos. 1551 1930. Quito: Imprenta de la Universidad Central.

Navarro Bonilla, Diego (2003). Las huellas de la lectura: marcas y anotaciones manuscritas en impresos de los siglos XVI a XVIII. En Antonio Castillo Gómez (ed.) Libro y lectura en la Peninsula Ibérica y América (siglos XIII a XVIII). Las huellas de la lectura: marcas y anotaciones manuscritas en impresos de los siglos XVI a XVIII. Valladolid, Junta de Castilla y León, pp. 243-287.

Orejuela, Manuel (1931 Enero-Marzo). Boletín de la Biblioteca de la Universidad 
Central. En Anales de la Universidad Central, No. 275, pp. 114-181.

Ponce Leiva, María Pilar (1998). La educación disputada: Repaso bibliográfico sobre la enseñanza universitaria en la Audiencia de Quito. En Estudios de historia social y económica de América, No. 11, pp. 137-149.

Rueda Ramírez, Pedro José (2000). La circulación de libros desde Europa a Quito en los siglos XVI-XVII. En Procesos: Revista Ecuatoriana de Historia, No. 15, pp. 3-20.

Sánchez Astudillo, Miguel (1959). Textos de catedráticos jesuitas en el Quito colonial: Estudio y bibliografía. Quito: Casa de la Cultura Ecuatoriana.

Stols, Alexandre (1953). Historia de la Imprenta en el Ecuador de 1755 a 1830. Quito: CCE.

Vargas, José María (1965). Historia de la cultura ecuatoriana. Quito: Casa de la Cultura Ecuatoriana.

Vásquez Hahn, María Antonieta (2005). Luz a través de los muros. Biografía de un edificio quiteño. Quito: FONSAL.

Villagómez, Juan A. (1912 Diciembre). "La Universidad Central de Quito":

I, en Anales de la Universidad Central, No. 6 (Nueva Serie), pp. 252-266.

II, en Anales de la Universidad Central, No. 7, pp. 275-285.

III, en Anales de la Universidad Central, No. 8, pp. 299-309.

IV, en Anales de la Universidad Central, No. 9-10, pp. 331-343.

V, en Anales de la Universidad Central, No. 28-29, pp. 386-396.

VI, en Anales de la Universidad Central, No. 32-33, pp. 475-490. 